\title{
Characterization of Complementary Feeding in Infants of Azogues, Biblián and Déleg
}

\author{
María Alejandra Aguirre Quezada ${ }^{1}$, María de los Ángeles Estrella González ${ }^{1}$, Andrés Alexis Ramírez-Coronel ${ }^{1,3}$, Pedro C. Mar- \\ tínez Suárez ${ }^{2,3}$, Mercedes Magdalena Sarmiento Pesántez ${ }^{1}$, Marina Cecilia \\ Andrade Molina ${ }^{1}$, Nancy Beatriz Cordero Zumba ${ }^{1}$. \\ ${ }^{1}$ Faculty of Nursing at the Catholic University of Cuenca, Azogues Campus. \\ ${ }^{2}$ Psychometry Laboratory of the Center for Research, Innovation and Technology Transfer (CIITT) of the \\ Catholic University of Cuenca. \\ ${ }^{3}$ Faculty of Clinical Psychology at the Catholic University of Cuenca
}

\begin{abstract}
Nursing children consume small amounts of food, the quality is essential and determines the importance of the complementary feeding. Parents must Access nutritional information objective to fix healthy habits that prevent diet-related diseases. Quantitative, correlational study of cross-section, participated 1760 boys and girls from one to three years of public child care units of the cantons Azogues, Bible and Deleg. (919 boys and girls 841 ). The measurements were frequency of consumption and eating behavior. The results of the $9.77 \%$ introduced foods other than breast milk at 4 months and the $62.26 \%$ did so at 6 months. Most consumed foods are rice, banana, chicken, broccoli, potato and lentils with average equivalent to the common category and at least consumed quinoa, grape, the rabbit, the zucchini and soy that are in any category. 86.82\% of researches say no selection for industrial cereal porridge feed. The results of this research are expected to provide relevant information on the food pattern of local children and enable child care institutions to provide specialized child nutrition support.
\end{abstract}

Keywords:- Complementary feeding, Consumption, infants, breast milk.

\section{INTRODUCTION}

Breastfed children consume small amounts of food; however, the quality of the food is paramount and thus determines the importance of complementary feeding (CF). The World Health Organization (WHO) defines CA as "the process that begins when breast milk is no longer sufficient to meet all the infant's nutritional needs and other foods are therefore needed to supplement it" (1). This period is ideal for: 1) promoting the ability to chew; 2) familiarizing the child with flavours, aromas and textures; and 3) consuming foods with a high density of nutrients (2).

After exclusive breastfeeding, it is not possible to cover energy, macro and micronutrient requirements through this form of encouragement. For this reason, since 2001, the WHO recommends that, without suspending breastfeeding, it is necessary to start CA from six months of age $(1,3)$
With the maintenance of the practice of breastfeeding the child from six months onwards, the introduction of other foods to cover energy, protein, lipid and micronutrient requirements is vital. However, the growing number of publications on effects on the nutritional status of children suggests that it is the responsibility of the father, mother or caregiver to establish appropriate feeding habits, but at the right age to generate significant and replicable learning throughout life (4-5-6-8).

The ages of six to eleven months represent an undisputed period of opportunities for work in favour of child nutrition, and it is ideal to be able to take advantage of the time so that the child acquires a taste for different tastes, textures and smells. Its application demands the understanding of this feeding phase in which the contribution of professionals is transcendental otherwise the inadequate CA will cause irreversible effects $(7,9,10,11,27)$.

The incidence of nutrition on development and growth is evident; providing the necessary energy and with the corresponding nutrients requires an important action of prevention of diet-related diseases $(12,13,14,25)$.

The age of introduction of complementary foods is a particularly important time in a child's development. The diet undergoes a radical change from a single food (breast milk) with fat as the main source of energy to a variety of foods required to meet nutritional needs $(15,16,23)$.

The diverse CA is the one that contains at least four food groups, among which the following stand out Cereals or tubers, legumes, milk derivatives: cheese, yogurt or breast milk substitutes, meats: red, fish, chicken, viscera, egg, fruits or vegetables $(18,19,23)$. In relation to dairy products, unmodified whole cow's milk is not indicated for CA, because of the possible association with blood loss through the faeces $(20,21)$.

The food group that is most difficult to consume is meat, an essential source of iron and zinc. When its ingestion, during the first years of life, through the diet is frequently inadequate, it causes a decrease in physical capacity and cognitive performance, and changes in behavior, among others (24). 
In Ecuador, the Ministry of Public Health has stated that it agrees with the recommendation of the WHO and educates the population in its health units so that children begin CA from the sixth month of life (25). It is unquestionable that $\mathrm{CA}$ is much more than simply introducing food for the child. It corresponds to a large window of opportunity for growth, affection and the establishment of healthy eating habits. In this context, the use of cereals to prevent energy deficiency and the proper selection of other food groups that in the right quantities will be the basis of future eating patterns. The purpose of this research was to characterize the complementary feeding of children attending public childcare units in the cantons of Azogues, Biblián and Déleg.

\section{METHODOLOGY}

The type of study corresponded to a quantitative, correlational, cross-sectional, quantitative-focused and nonexperimental research. The study population corresponds to the following cantons: Azogues, Biblián and Déleg belong to the province of Cañar, which is located in the south of Ecuador, in the geographical area known as the interAndean region or sierra, mainly on the Cañar valley. It was carried out in collaboration and under the auspices of the Azogues District 1 of the Ministry of Economic and Social Inclusion, with 51 childcare units distributed in the three cantons. At the date of the data collection, there were 2403 children aged 1 to 3 , with an error of $1.5 \%$ and a confidence level of $98.5 \%$.

All children enrolled in the study were included, but all those who entered the program during the research process were excluded. In addition, one representative per child was included and informed consent is available. To collect the information, the questionnaire designed by Freire and collaborators (2012) was used, which included categories corresponding to socio-economic conditions, eating behaviour and frequency of consumption, established in the National Health and Nutrition Survey of Ecuador.

The socio-economic status variable was studied through the level of education of the mother or caregiver, characteristics of the dwelling and occupation of the head of household. Breast milk consumption was measured through the options Yes - No. The age at which she began to receive food other than breast milk/formula was the age scale represented by $4,5,6.7$ months, and the other options, she does not remember. The age at which food groups were introduced was associated with the range of 4-12 months with cereals, fruits (except citrus), meats, root vegetables, egg yolk and legumes and the other options were added, does not recall and that food group is not given.

The frequency of consumption variable assessed the consumption and the frequency of consumption, considering it to be very frequent if the consumption is once a day or more than twice a day, frequent two or three times a week, infrequent once a week, possibly once a month and never. The consumption of industrial cereal porridges corresponded to the categories Yes - No. The causes of the non-consumption of industrial porridges were determined using the options: high cost, taste not accepted by children, products are not natural and not easily available. In the data analysis, the calculation of central tenure measures was performed and the Spearman coefficient was used to determine the correlation, using the SPSS version 25 statistical program.

\section{RESULTS}

By applying Spearman's correlation coefficient by hierarchy, to know the degree of association of the variables level of education of the mother/carer, consumption of breast milk, level of social class of the head of household and consumption of industrial cereal porridge; an average positive correlation is concluded (table 1).

\begin{tabular}{|c|c|c|c|c|c|}
\hline \multirow{3}{*}{$\begin{array}{c}\text { Mother/caregiver's level } \\
\text { of education }\end{array}$} & \multicolumn{4}{|c|}{ Consumo de leche materna } & \multirow[t]{3}{*}{$p$} \\
\hline & \multicolumn{2}{|c|}{ Yes } & \multicolumn{2}{|c|}{ No } & \\
\hline & f & $\%$ & $\mathrm{f}$ & $\%$ & \\
\hline None & 1 & 0,06 & 0 & 0 & \multirow{7}{*}{0.313} \\
\hline $\begin{array}{c}1-3 \text { years of primary } \\
\text { school }\end{array}$ & 64 & 3,64 & 3 & 0,18 & \\
\hline $\begin{array}{c}4-5 \text { years of primary } \\
\text { school }\end{array}$ & 520 & 29,54 & 2 & 0,12 & \\
\hline $1-3$ years of high school & 242 & 13,74 & 5 & 0,28 & \\
\hline $4-6$ years of high school & 585 & 33,24 & 45 & 2,56 & \\
\hline Superior & 203 & 11,52 & 90 & 5,12 & \\
\hline Total & 1615 & 91,74 & 145 & 8,26 & \\
\hline
\end{tabular}




\begin{tabular}{|c|c|c|c|c|c|}
\hline \multirow{3}{*}{$\begin{array}{l}\text { Social class level of the } \\
\text { head of household }\end{array}$} & \multicolumn{4}{|c|}{ Consumption of industrial cereal porridge } & \\
\hline & \multicolumn{2}{|c|}{ Yes } & \multicolumn{2}{|c|}{ No } & \\
\hline & $\mathrm{f}$ & $\%$ & $\mathrm{f}$ & $\%$ & \\
\hline Upper-middle stratum & 121 & 6,88 & 133 & 7,55 & \multirow{5}{*}{0,429} \\
\hline Middle layer & 87 & 4,94 & 284 & 16,14 & \\
\hline High popular stratum & 18 & 1,02 & 629 & 35,74 & \\
\hline Low popular stratum & 6 & 0,34 & 482 & 27,39 & \\
\hline Total & 232 & 13,18 & 1528 & 86,82 & \\
\hline
\end{tabular}

Table 1:- Educational level of the mother or caregiver and social class level of the head of household.

The age at which she began to receive food other than breast milk is presented in Table 2, highlighting $9.76 \%$ and $62.27 \%$ corresponding to 4 months and 6 months respectively, the average age of onset of CA is 5.86 months.

The description of the food groups and age of consumption is presented in Table 2, observing that the sequence with which they are added to the diet is done in a disorderly manner and early in certain cases or late in another. This disfigures the proposed international scheme. It is also identified that the food group that parents decide not to include in the CA is meat and egg yolk, a situation that warns of an inadequate contribution of nutrients from an early age. When observing the introduction of food groups in relation to age, it is observed that when CA begins, the selection of cereals, fruits, vegetables and tubers predominates. Unlike groups such as legumes and meats. The sequence of introduction of egg yolk, meats and legumes generates interest, as they are introduced during all the months of the study and they even profile as those who do not select for CA. Not offering cereals could suggest some relation with celiac situations probably. The groups that show similar behaviour in CA in this study population are fruits, vegetables and tubers.

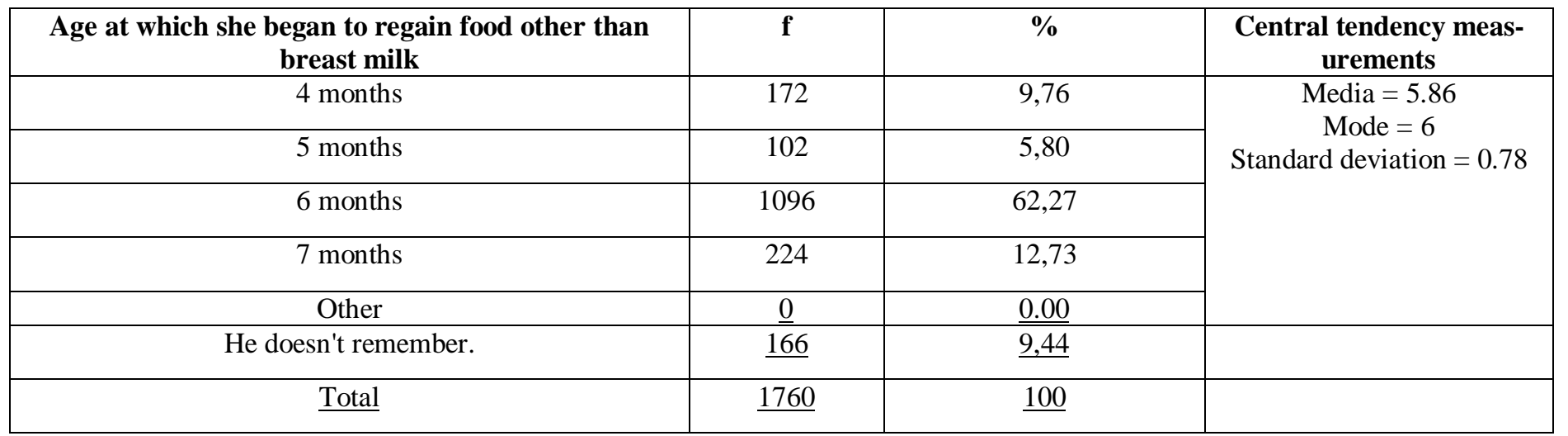

Table 2:- Age at which she started receiving food other than breast milk

The summary of the consumption frequency statistics for the food groups is detailed, highlighting that the most consumed foods are rice, banana, chicken, broccoli, potato and lentil with averages equivalent to the very frequent category and the least consumed are quinoa, grapes, rabbit, zucchini and soya which are located in the eventual indicator. The consumption of industrial cereal porridges and the description of the causes of the lack of consumption are presented in table 5 , observing that $86.82 \%$ of the people surveyed state that they do not select industrial cereal porridges for their diet and among the causes they point out that children do not like the flavours, they are not natural products, they are not easily obtained and the cost. The perception of the father, mother or caretaker in relation to eating behavior was evaluated, highlighting that $14.44 \%$ and $14.99 \%$ report that children rarely and never respectfully have an appetite, as described.

\section{DISCUSSION}

The present study identified, the early introduction of foods before six months, complexity in the sequence of introduction of food groups and even foods that are not included in the CA plans, situations that could impact on the nutrition of infants and that move away from the compliance with the international provisions of the WHO (1).

By observing the characterization of the group investigated, an early displacement of breastfeeding can be inferred at this important stage, and it should be emphasized that the foods produced in the area are eventually selected, despite their excellent nutritional properties and the availability that exists, demonstrating a lack of cultural relevance in this selection. It is important to recognize that at this stage of life, children depend on the food provided by the family and it will manifest the practice of raising each household that reaffirms the eating habits of the nucleus and will also maintain a relationship with the family economy, since foods rich in nutrients are 
often of animal origin, are expensive in relation to basic foods such as rice and do not allow them to be acquired on a regular basis $(15,21,24)$.

In this study the average age of food incorporation is 5.86 months. In general, what is evident is that inadequate CA patterns could make visible associated risks and limit growth and development. These results are consistent with a study conducted in Chile that showed that $42.2 \%$ of infants began complementary feeding with the simultaneous introduction of foods of vegetable origin (cereals and/or fruits and/or vegetables) and animal origin (chicken) $(5,6,19)$.

The results are not related to studies in the Amazon region of Brazil that showed early introduction of carbohydrate-rich foods along with cow's milk and irregular intakes of fruits, vegetables and meat 6 . Furthermore, they are similar to those observed in the Lactation, Nutritional Status and CA Survey carried out in Uruguay where apple consumption was predominant $(7,8,9)$.

Despite the fact that data on CA initiation at 4 months are available, when compared with the Bolivian Andes, it was observed that $39 \%$ had initiated complementary feeding in the first three months, mainly with potato and chuño (dehydrated potato), it does not agree 8 . The percentage of children who incorporated foods before the age of six months does not agree with the research conducted in Chile, where the percentage of breastfed infants who had incorporated solid foods was only about $7 \%$. The diversity of children's diets in $\mathrm{CA}$ is fundamental in order to cover nutritional requirements, avoid deficiencies and generate adequate habitats that allow for the fulfillment of macro and micronutrient requirements. To achieve this, the strategy should focus on nutritional education. Compliance can influence the health status of individuals during later stages such as adolescence and adulthood $(24,27)$.

\section{ACKNOWLEDGEMENT}

To the Psychometry Laboratory of the Center for Research, Innovation and Technology Transfer of the Catholic University of Cuenca (CIITT) and to the Nursing Career of the Catholic University of Cuenca, Azogues headquarters.

\section{REFERENCES}

[1]. World Health Organization. Guiding principles for feeding non-breastfed children 6-24 months of age. World Health Organization; 2005.

[2]. Jiménez R, Curbelo JL, Peñalver R. Relation of the type of feeding with some variables of growth, nutritional status and morbidity of the infant. Medical Colombia. 2015: 19-25.

[3]. Caulfield LE, Esteban RA, Rivera JA, Musgrove P \&Negro RE. Stunting, Wasting, and Micronutrient Deficiency Disorders. Chapter 28 Washington (DC): World Bank; 2006.
[4]. Castro TG, Baraldi LG, Muniza PT \& Cardoso MA. Dietary practices and nutritional status of 0-24-monthold children from Brazilian Amazonia. Public Health Nutr. 2015: 35-42.

[5]. Cruz Y, Jones AD, Berti PR \& Larrea S. Breastfeeding, complementary feeding and infant malnutrition in the Andes of Bolivia. Arch Latinoam Nutr. 2016: 714.

[6]. Bove MI \& Cerruti F. Breastfeeding survey, nutritional status and complementary feeding. UNICEF, Uruguay; 2007.

[7]. Reyes C, Atalah E \& Castillo C. Effectiveness of the Breastfeeding Program. National Breastfeeding Commission. Ministry of Health. Chile; 2005.

[8]. Santamaria A. Dietary habits of Spanish and Chilean infants. Doctoral Thesis University of Barcelona; 2015.

[9]. World Health Organization. Guiding principles for complementary feeding for the breastfed child. Division of Health Promotion and Protection, Food and Nutrition Program. Washington: Pan American Health Organization/World Health Organization; 2003.

[10]. UNICEF. Infant and young child feeding. Nutrition section, programmes. New York: United Nations Children's Fund (UNICEF); 2016.

[11]. Agostoni C, Decsi T, Fewtrell M, Goulet O, Kolacek S, Koletzko B, et al. ESPGHAN Committee on Nutrition. Complementary Feeding: A Commentary by the ESPGHAN Committee on Nutrition. J Pediatr Gastroenterol Nutr. 2018:46 -110.

[12]. De Silva D, Geromi M, Halken S, Host A, Panesar S, Muraro A, et al. Primary prevention of food allergy in children and adults: systematic review. Allergy. 2016: 69.

[13]. Koninckx CR, Dalmau SJ, Moreno VJ, Díaz MJ, Castillejo G, Polanco AI. The introduction of gluten in the infant's diet. Recommendations of a group of experts. An PediatrBarc. 2015.

[14]. Touzani K, Bodnar RJ, Sclafani A. Neuropharmacology of learned flavored preferences. Pharmacol Biochem Behav. 2010.

[15]. Ministry of Health. Official Mexican Standard NO043-SSA2-2005. Basic health services. Promotion and education for health in alimentary matters. Criteria to provide guidance. Official diary. 2016.

[16]. Pearce J \& Langley-Evans SC. The types of food introduced during complementary feeding and risk of childhood obesity: a systematic review. Int J Obes (Lond); 2013.

[17]. Olaya G, Lawson M \& Fewtrell M. Efficacy and safety of new complementary feeding guidelines with an emphasis on red meat consumption: A randomized trial in Bogota, Colombia. Am J Clin Nut. 2017: 983.

[18]. Deming DM, Afeiche MC, Reidy KC, Eldridge AL, Villalpando-Carrión S. Early feeding patterns among Mexican babies: findings from the 2012 National Health and Nutrition Survey and implications for health and obesity prevention. BMC Nutrition; 2015.

[19]. Brown A \& Rowan H. Maternal and infant factors associated with reasons for introducing solid foods. Matern Child Nutr. 2016: 121-145. 
[20]. Pan American Health Organization. Guiding principles for the feeding of non-breastfed children between 6 and 24 months of age. Geneva: World Health Organization; 2008.

[21]. Pardío J. Complementary Feeding of the Child from Four to 24 Months of Age Mexico: Editorial Médica Panamericana; 2015.

[22]. Torrejón C, Osorio J, Vidoso M, Castillo C. Feeding of the child under 2 years old. Recommendations of the nutrition branch of the Chilean Society of Pediatrics. Rev Chil Ped. 2005:76-91.

[23]. Van-Dijck M, Hunnius S, Van-Geert P. Variability in eating behavior throughout the weaning period. Appetite. 2009:52-70.

[24]. Solomons NW. Iron Deficiency and Deficiencies of Other Nutrients. Pediatric nutrition in practice. Basel Karger. 2008: 37-41.

[25]. Krebs NF, Westcott JE, Butte N, Robinson C, Bell M, Hambidge KM. Meat as a first complementary food for breastfed infants: feasibility and impact on zinc intake and status. J Pediatr Gastroenterol Nut. 2006: 4254.

[26]. Schwartz C, Scholtens PA, Lalanne A, Weenen H, Nicklaus S. Development of healthy eating habits early in life. Review of recent evidence and selected guidelines. 2011: 796-807.

[27]. Dewey KG \&Brown KH. Update on Technical Issues Concerning Complementary Feeding of Young Children in Developing Countries and Implications for Intervention Programs. Food Nutr. 2003: 24-28.

[28]. Ministry of Public Health of Ecuador. Feeding guide for children under 2 years. 2013. 